\title{
Burnout, psychological disorders and perceived quality of care among pediatricians in the western region of Saudi Arabia
}

\author{
RANA MOHAMMED RAHIMALDEEN ${ }^{1, A-G}$, KHALID TALAL ABOALSHAMAT², A, c-E \\ ORCID ID: 0000-0002-2450-5746 \\ ORCID ID: 0000-0001-5957-8681 \\ BAYAN MOHAMMED ALMEHMADI 3, B-D, BAYADIR MOHAMMED ALJUBAIRY4, в, E, F, \\ ORCID ID: 0000-0003-4501-7618 \\ ORCID ID: 0000-0002-1367-9265 \\ ALJAWHARAH MOHAMMED ALJOHANI5, B, F, KHULUD IDRIS NUR ${ }^{4,8, E, ~ F, ~}$ \\ ORCID ID: 0000-0001-8267-8787
} HIFA SULIMAN ALSUHAIBANY ${ }^{6, \text { A, B, E, F }}$

ORCID ID: 0000-0002-6436-8045

${ }^{1}$ Batterjee Medical College, Jeddah, Saudi Arabia

${ }^{2}$ Dental Public Health Division, Preventative Dentistry Department, College of Dentistry, Umm AlQura University,

Makkah, Saudi Arabia

${ }^{3}$ Hera General Hospital, Makkah, Saudi Arabia

${ }^{4}$ Ibn Sina National College, Jeddah, Saudi Arabia

${ }^{5}$ National Guard Hospital, Jeddah, Saudi Arabia

${ }^{6}$ Ibn Sina National College for Medical Studies, Jeddah, Saudi Arabia

A - Study Design, B - Data Collection, C - Statistical Analysis, D - Data Interpretation, E - Manuscript Preparation, F - Literature Search, G - Funds Collection

Summary Background. Psychological burden is well documented among medical physicians worldwide.

Objectives. This study aims to assess the prevalence of psychological distress and perceived quality of care among pediatricians in the western region of Saudi Arabia.

Material and methods. A descriptive cross-sectional study design was used to collect data from 251 pediatricians in the western region of Saudi Arabia. The data was collected using a self-reported questionnaire using the Copenhagen Burnout Inventory to measure burnout and DASS-21 to measure depression, anxiety and stress. In addition, self-perceived care was measured using two validated questions.

Results. Pediatricians had high levels of psychological distress, including burnout (80.5\%), depression (66.5\%), anxiety (71.3\%) and stress (55\%). $21.6 \%, 41.1 \%$, and $16.7 \%$ of pediatricians were classified with severe or extremely severe depression, anxiety or stress, respectively. Female, junior and younger pediatricians had higher levels of burnout, depression, anxiety and stress. A total of $45.8 \%$ to $48.6 \%$ of pediatricians believed that adverse work conditions and workloads always or often lead to lost days of work and reduced work quality.

Conclusions. Pediatricians in Saudi Arabia have high levels of psychological distress, with the most affected subgroups being female, junior and young pediatricians. Hospitals should provide psychological support to improve the psychological well-being of pediatricians.

Key words: psychological burnout, depression, anxiety, psychological distress, Saudi Arabia.

Rahimaldeen RM, Aboalshamat KT, Almehmadi BM, Aljubairy BM, Aljohani AM, Nur KI, Alsuhaibany HS. Burnout, psychological disorders and perceived quality of care among pediatricians in the western region of Saudi Arabia. Fam Med Prim Care Rev 2021; 23(2): 209-214, doi: https://doi.org/10.5114/fmpcr.2021.105928.

\section{Background}

Psychological distress is well documented among medical physicians worldwide, as reported in many systematic reviews [1-4]. Literature highlights the impact of poor psychological health on healthcare delivery and physicians' outcomes, which include increased medical errors, decreased professionalism, quality of care and care safety, as well as decrease patient outcomes and satisfaction [5-12]. An estimate of the cost of burnout-related cutbacks and early retirement with physicians indicates total losses of at least C\$213 million in patient services in Canada [13].

This psychological distress is also well known among pediatricians, manifesting as burnout, depression, stress, anxiety $[9,12,14]$ and other types of psychological burden. This poor psychological health was attributed to the high levels of responsibilities, extra working hours, life-work balance, excessive workloads and worsened effort-reward imbalances [12, 14]. In fact, around $41 \%$ of pediatricians have seriously considered quitting their careers due to such psychological burdens [14]. Studies in literature are contradictory with regard to the levels of psychological distress among pediatricians as compared to other medical specialties. A study in Pakistan indicated that pediatricians have more psychological problems than other medical specialties [15], while other studies in the United States and Egypt found the opposite $[16,17]$. This can be due to differences in culture and healthcare systems between countries.

The most commonly investigated psychological construct in literature studying pediatricians was burnout [12, 16, 18-24]. Burnout is a psychological syndrome characterized by a psychosomatic lack of energy, diminishing professional performance and skepticism [25]. The prevalence of burnout among pediatricians varies from country to country. For example, there is a $29 \%$ to $71 \%$ prevalence rate in Brazil [19], $26.7 \%$ to $74 \%$ in the 
United States [18, 20-24], 18.75\% in Egypt [16] and 10.2\% in Germany [12]. A study showed that the most common cause of burnout among physicians was administrative work, paperwork while conducting regular clinical visits and consultations with parents about their child's development [8].

Many factors influence the prevalence of burnout. Time is one important factor, with studies showing that the prevalence of burnout among pediatricians had fluctuated over time; it was $45.5 \%$ in 2011 , went up to $54.4 \%$ in 2014 , then lowered to $43.9 \%$ in 2017 . Another longitudinal study showed that the prevalence of burnout increased in the pediatric residency program from one year to the next [20]. Furthermore, studies have emphasized that pediatricians in intensive care units (ICUs) have higher burnout rates than other pediatricians $[12,19,24,26]$. Resident pediatricians also have higher rates of burnout than senior pediatricians $[12,18]$. According to one study, the variables of gender, having children and race had no relationship to burnout prevalence in the United States [23].

A few studies have investigated other psychological problems among pediatricians, including depression, anxiety and stress. Studies have indicated that the prevalence of depression among pediatricians was $20 \%$ in the United States [18] and $29 \%$ in the Netherlands [14]. Anxiety was found to have a $24 \%$ rate of prevalence among pediatricians in the Netherlands [14], and the same study found that around $80 \%$ of pediatricians have experienced some adverse events that caused them extreme levels of stress, including an incorrect diagnosis, a child's death, a seriously ill child, decision-making difficulties and suspicion of child abuse with an aggressive response from the parents [14].

However, while researchers have investigated these psychological distresses among medical students in Saudi Arabia [27-30], similar research investigating pediatricians is lacking.

\section{Objectives}

The objective of this study was to assess the prevalence of burnout, psychological disorders and perceived lowered quality of care among pediatricians in the western region of Saudi Arabia.

\section{Material and methods}

\section{Study design}

The study design is a descriptive cross-sectional study aimed at assessing the prevalence of burnout, psychological disorders and perceived lowered quality of care among pediatricians in the western region of Saudi Arabia.

\section{Setting}

Data was collected from March to April 2020 from pediatricians who worked in government and private hospitals in the western region of Saudi Arabia. The study used an English language self-administered questionnaire that was distributed face to face as paper copies. A convenience sample was used. Written signed consent was obtained from each participant before having them answer the questionnaire. Any information that would reveal the identity of the participant was destroyed, and all data was collected without revealing any personal information.

\section{Participants}

The participants were pediatric consultants, specialists, residents and general practitioners working in pediatric departments. Retired pediatricians and interns in the pediatric rotation were excluded. Participants were identified with their hospital badge.

\section{Study size}

We used the following sample size calculation $n=z^{2 *} p(1$ $p) / e^{2}$, and we used the following measures: a precision level of $5 \%$, confidence level of $90 \%$ and estimated prevalence of $71 \%$ (as the highest prevalence in previous literature among pediatricians [19]). Accordingly, 225 participants were required as the minimum number in this study.

\section{Variables and measures}

The questionnaire was composed of 40 questions divided into four sections: demographics, burnout, psychological distress (depression, anxiety and stress) and perceived quality of care. The demographic section asked about gender, nationality, marital status, family monthly income, job status, number of children, professional tenure, typical work shift, number of hours worked per week and number of vacation days taken in the last year.

Section two investigated burnout using the Copenhagen Burnout Inventory (CBI) with a Cronbach's alpha of 0.87 [31]. The $\mathrm{CBI}$ consists of seven items with a 5-point range for answers, where always $=100$, often $=75$, sometimes $=50$, seldom $=25$, and never/almost never $=0$. The average score of the seven questions was used to find a score, with an average of more than 50 points considered to be moderate to high levels of burnout [32], and an average of 50 points or less was considered as low levels or no burnout.

Section three measured depression, anxiety and stress using DASS-21 [33], with Cronbach's alpha values of 0.82 to 0.9 for the subscales [34]. DASS-21 is composed of 21 items, and the total score of unique combinations of seven items on the scale represent depression, anxiety or stress. Scores for depression, anxiety and stress are calculated by totaling the scores for the relevant items. A 4-point scale was applied, where $0=$ "Did not apply to me at all", 1 = "Applied to me to some degree or some of the time", 2 = "Applied to me to a considerable degree or a good part of the time", and 3 = "Applied to me very much or most of the time". The score was then multiplied by two and classified as no psychological problems, mild psychological problems, moderate psychological problems, severe psychological problems or extremely severe psychological problems, according to the subscale cutoff points [33].

Section four measured the perceived quality of care using a two-item measure from a validated German questionnaire $[12,35]$, with a 5-point scale applied for answers $(0=$ not at all to 4 = to a very great extent). The two items were "My workload frequently leads to reduced quality of work" and "Adverse work conditions frequently lead to a loss of quality".

\section{Statistical methods}

Data analysis was conducted on SPSS v.21 software, with ANOVA, linear and logistic regression, $t$-Test and chi-square tests being used. Statistics were generated by frequency tables and calculating the mean (M) and standard deviations (SDs). A $p$-value of 0.05 was considered significant.

\section{Ethical consideration}

The study obtained the positive opinion of the Ethics Committee (IRB registration number KACST,KSA:H-02-J-002 Research Number:1390 Type of review: Expedited).

\section{Results}

The questionnaires were distributed to 386 participants, and 251 (65\%) completed the survey. The mean age of participants was 31.1 years $(S D=7.44)$. The mean number of hours worked per week was $56.22(S D=19.58)$. The participants had a vacation in the previous year for a mean of 34.14 days 
$(S D=16.47)$. Other demographic data is shown in Table 1. There were more female participants $(62.9 \%)$ than male participants (37.1\%). The majority of participants were Saudi (84.1\%). About $58.1 \%$ had no children, $27.5 \%$ had one to two children, and only $14.3 \%$ had three children or more. The percentage of married participants (51\%) was close to unmarried (49\%). Most participants $(79.1 \%)$ had a family income of 10 to 30 thousand Saudi Riyal. Most of the participants (70.5\%) were residents. The majority of participants (82.1\%) were working the morning shift, as shown in Table 1.

\begin{tabular}{|l|l|l|l|}
\hline \multicolumn{3}{|l|}{ Table 1. Participant demographic data } \\
\hline Demographic variable & Category & Number & $\%$ \\
\hline Gender & male & 93 & 37.10 \\
& female & 158 & 62.90 \\
\hline Nationality & Saudi & 211 & 84.10 \\
& non-Saudi & 40 & 15.90 \\
\hline Number of children & none & 146 & 58.10 \\
& $1-2$ & 69 & 27.50 \\
& 3 or more & 36 & 14.30 \\
\hline Marital status & unmarried & 123 & 49 \\
& married & 128 & 51 \\
\hline Family income (Saudi & less than 10,000 & 16 & 6.40 \\
Riyal) & $10,000-30,000$ & 196 & 78.10 \\
& more than 30,000 & 39 & 15.50 \\
\hline Position & intern & 5 & 2 \\
& service & 18 & 7.20 \\
& resident & 177 & 70.50 \\
& specialist & 37 & 14.70 \\
& consultant & 14 & 5.60 \\
\hline Type of shift & morning & 206 & 82.10 \\
& evening or night & 45 & 17.90 \\
\hline
\end{tabular}

\section{Psychological distress}

The mean $\mathrm{CBI}$ scores for the participants were 60.75 $(S D=16.77)$. According to the cutoff point, $80.5 \%$ of the participants were experiencing high levels of burnout ( $>50$ points). The mean for depression was $13.67(S D=8.9)$. For anxiety, the mean was $13.09(S D=8.3)$, and for stress, the mean was 16.9 $(S D=8.4)$. The prevalence of depression, anxiety and stress are displayed in Table 2. Regarding depression, $10.4 \%$ had extremely severe depression, and $11.2 \%$ had severe depression. Regarding anxiety, $22.7 \%$ had extremely severe anxiety, and $18.3 \%$ had severe anxiety. Regarding stress, only $5.2 \%$ had extremely severe stress, and $11.6 \%$ had severe stress. In fact, the percentages of participants with normal levels of depression, anxiety and stress are $33.5 \%, 28.7 \%$ and $45 \%$, respectively, as detailed in Table 2 .

\begin{tabular}{|l|l|l|l|}
\hline \multicolumn{4}{|l|}{ Table 2. Prevalence levels of depression, anxiety and stress } \\
\hline & \multicolumn{3}{|l|}{ Psychological distress } \\
\hline Level & $\begin{array}{l}\text { Depression } \\
\text { Number (\%) }\end{array}$ & $\begin{array}{l}\text { Anxiety } \\
\text { Number (\%) }\end{array}$ & $\begin{array}{l}\text { Stress } \\
\text { Number (\%) }\end{array}$ \\
\hline Normal & $84(33.5)$ & $72(28.7)$ & $113(45.0)$ \\
\hline Mild & $45(17.9)$ & $17(6.8)$ & $52(20.7)$ \\
\hline Moderate & $68(27.1)$ & $59(23.5)$ & $44(17.5)$ \\
\hline Severe & $28(11.2)$ & $46(18.3)$ & $29(11.6)$ \\
\hline Extremely severe & $26(10.4)$ & $57(22.7)$ & $13(5.2)$ \\
\hline
\end{tabular}

The total percentages might not add up to $100 \%$ due to foundation.

According to the $t$-Test, there were no significant relationships between burnout, depression, anxiety or stress and marital status, nationality and type of shift. The results of the $t$-Test, ANOVA and Pearson's linear regression for relationships between burnout, depression, anxiety or stress and gender, position, number of children, age, working hours per week and days of vacation per year are shown in Tables 3 and 4. In fact, females had significantly higher scores for burnout, depression, anxiety and stress. Similarly, juniors participants (intern, service and resident) had higher scores for burnout, depression, anxiety and stress. When examining scores in relation to number of children, only participants who had three or more children had significantly lower burnout scores than participants without children and participants with one to two children. However, there were no differences in scores of depression, anxiety or stress. Age had a significant inverse relationship with burnout, depression and stress but not with anxiety. The number of working hours per week had a significant direct relationship with burnout but an inverse relationship with anxiety. Moreover, days of vacation per years had a significant inverse relationship with burnout but no effect on depression, anxiety or stress.

\begin{tabular}{|c|c|c|c|c|c|}
\hline \multirow[b]{2}{*}{ Demographic variable } & \multirow[b]{2}{*}{ Category } & \multicolumn{4}{|c|}{ Psychological distress } \\
\hline & & \begin{tabular}{|l} 
Burnout \\
Mean (SD)
\end{tabular} & $\begin{array}{l}\text { Depression } \\
\text { Mean (SD) }\end{array}$ & $\begin{array}{l}\text { Anxiety } \\
\text { Mean (SD) }\end{array}$ & $\begin{array}{l}\text { Stress } \\
\text { Mean (SD) }\end{array}$ \\
\hline Gender & $\begin{array}{l}\text { male } \\
\text { female }\end{array}$ & $\begin{array}{l}57.75(16.95)^{*} \\
62.52(16.47)\end{array}$ & $\begin{array}{l}11.89(8.15)^{*} \\
14.72(9.19)\end{array}$ & $\begin{array}{l}11.35(7.98)^{*} \\
14.12(8.34)\end{array}$ & $\begin{array}{l}14.6(7.15)^{*} \\
17.9(8.8)\end{array}$ \\
\hline Position & $\begin{array}{l}\text { seniors (specialist or con- } \\
\text { sultant) } \\
\text { juniors (intern, service, } \\
\text { resident) }\end{array}$ & $\begin{array}{l}50.42(18.44)^{*} \\
63.39(15.29) \\
\end{array}$ & $\begin{array}{l}10.04(8.03)^{*} \\
14.6(8.91)\end{array}$ & $\begin{array}{l}10.24(8.24)^{*} \\
13.83(8.18) \\
\end{array}$ & $\begin{array}{l}13.29(7.14)^{*} \\
17.5(8.47) \\
\end{array}$ \\
\hline Number of children & $\begin{array}{l}\text { no children } \\
1-2 \text { children } \\
3 \text { or more children }\end{array}$ & $\begin{array}{l}61.11(15.49) \\
63.72(18.18) \\
53.67(17.46)^{* *}\end{array}$ & $\begin{array}{l}60.76(16.78) \\
14.3(8.78) \\
13.86(9.08)\end{array}$ & $\begin{array}{l}10.78(8.81) \\
13.67(8.91) \\
13.56(8.01)\end{array}$ & $\begin{array}{l}12.9(8.71) \\
11.61(8.72) \\
13.1(8.30)\end{array}$ \\
\hline
\end{tabular}

* $p<0.05$;** Participants who had three or more children had significantly lower burnout scores than participants without children and participants with one to two children.

\begin{tabular}{|l|l|l|l|l|}
\hline \multicolumn{2}{|l}{ Table 4. Correlation between burnout, depression, anxiety and stress and age, working hours and days of vacation } \\
\hline & Psychological distress & Depression & Anxiety & Stress \\
\hline Demographic variable & Burnout & $-0.158^{*}$ & -0.113 & $-0.136^{*}$ \\
\hline Age & $-0.21^{*}$ & -0.099 & $-0.156^{*}$ & -0.078 \\
\hline Working hours per week & $0.252^{*}$ & 0.076 & 0.045 & 0.043 \\
\hline Days of vacation per year & $-0.128^{*}$ & &
\end{tabular}

$* p<0.05$ using Pearson's linear regression; the minus sign means it is an inverse correlation. 


\section{Perceived quality of care}

The participants were asked two questions about how adverse working conditions and workloads lead to reduced quality of work, and the answers are shown in Table 5. The participants reported (always $(15.5 \%)$ or often $(30.3 \%)$ ) that the adverse working conditions led to loss of work quality. The participants also reported (always $(21.1 \%)$ or often $(27.5 \%))$ that workload led to reduced work quality.

\begin{tabular}{|c|c|c|}
\hline \multirow[b]{2}{*}{ Level } & \multicolumn{2}{|c|}{ Quality of care question } \\
\hline & $\begin{array}{l}\text { Do your adverse } \\
\text { working conditions } \\
\text { frequently lead to } \\
\text { loss of quality? } \\
n(\%)\end{array}$ & $\begin{array}{l}\text { Does your workload } \\
\text { frequently lead to re- } \\
\text { duced work quality? } \\
n(\%)\end{array}$ \\
\hline Always & $39(15.5)$ & $53(21.1)$ \\
\hline Often & $76(30.3)$ & 69 (27.5) \\
\hline Sometime & $67(26.7)$ & $80(31.9)$ \\
\hline Seldom & $51(20.3)$ & $31(12.4)$ \\
\hline $\begin{array}{l}\text { Never/almost } \\
\text { never }\end{array}$ & $18(7.2)$ & $18(7.2)$ \\
\hline
\end{tabular}

\section{Discussion}

This study aimed to assess the prevalence of burnout, depression, anxiety, stress and lowered perceived quality of care among pediatricians in western regions of Saudi Arabia. The results showed that these pediatricians had a substantial prevalence of psychological distress. Four out of five pediatricians suffered from burnout. The proportions of pediatricians suffering from depression, anxiety or stress were $66.5 \%, 71.3 \%$ and $55 \%$, respectively. It is noteworthy that the proportions of pediatricians who were classified with severe or extremely severe depression, anxiety or stress were $21.6 \%, 41.1 \%$ and $16.7 \%$, respectively. Resident females were the most affected subgroup, and around half of the pediatricians believed that adverse working conditions and heavy workloads led to lower work quality.

Our results indicated that $80.5 \%$ of the participants suffered from burnout. This is higher than all previous studies of pediatricians conducted in Brazil (29\%-71\%) [19], the United States (26.7\%-74\%) [18, 20-24, 36], Germany (10.2\%) [12] and Egypt (18.75\%) [16]. Current data cannot explain the reason for this difference. One explanation might be the difference in the measure of burnout, as many of the previous studies used the Maslach Burnout Inventory (MBI) [37]. The reason for using the $\mathrm{CBI}$ instead of the $\mathrm{MBI}$ in this study is that the $\mathrm{MBI}$, despite being the most commonly used to measure burnout, has been criticized by many authors for being available as a commercial tool $[37,38]$. It might be easier for a researcher to use MBI services after purchasing help with analyzing the data, which might have made the $\mathrm{MBI}$ used more commonly. Furthermore, the $\mathrm{MBI}$ measures reductions in personal achievements, experiences of depersonalization and emotional exhaustion for people who work in the human services sectors [37], and some articles have argued that personal achievement and depersonalization do not reflect burnout [31, 39]. In fact, the CBI was found to surpass the $\mathrm{MBI}$ mainly in considering burnout as a fatigue phenomenon [31, 39].

The second factor causing the difference in these results may be the cultural differences between the health care systems of different countries. In fact, this is similar to a previous study that measured burnout among medical students in Saudi Arabia [27] and indicated that the percentage of burnout is higher there than in other countries. It is suggested that further comparative studies be conducted using a unified instrument to give external validity to the results.

The prevalence of depression, anxiety and stress in the present study was higher than had been reported in any other study conducted in the United States and the Netherlands [14, 18]. The difference here might again arise from the cross-country differences and the different scales used. When we compare our results with previous studies conducted in Saudi Arabia that also used DASS-21, but were among medical students [27, 29], we found similar percentages for depression and anxiety. In fact, our results are alarming by revealing that two out of five pediatricians had severe or extremely severe anxiety, and one out of five had severe or extremely severe depression. This result needs further justification and explanation. One of the important aspects to clarify is that while the data collection was conducted during the emergence of the coronavirus pandemic [40], and recent articles had emphasized that the pandemic created high levels of psychological distress among health care workers in China $[41,42]$, it is important to note that China was the first country to be affected by the pandemic, but Saudi Arabia was not affected until later. Therefore, attributing the high levels of psychological distress in this study to the coronavirus pandemic is likely not warranted.

In terms of demographic variables, females, being junior pediatricians or younger pediatricians were found to be more distressed than males, specialists/consultants or older participants. While one previous study [23] had different conclusions regarding females, several prior studies have reported poorer psychological health (including suicidal thoughts) among females than among males [43-45]. This might be because women were found to be more vulnerable and exposed to stressful events and emotional problems [46]. Moreover, our data is in line with a previous study that found senior pediatricians had better psychological health than those younger $[12,18]$.

With regard to perceived quality of care, our data indicates that working with psychological distress does affect the quality of pediatricians' work. This can be serious, because it could lead to further problems that affect patient safety. Therefore, it is recommended that attention should be paid to enhance the working enviroment based on preparation along with ways to offer incentives and benefits. For example, through appreciation accomplishments of junior physicians along with ways to offer incentives and benefits through, for example, appreciation, constructive reviews, encouragement, job flexibility and autonomy to promote well-being for physicians $[47,48]$. It is also recommended that more psychological programs [49], assessments and support be offered to reduce the high levels of psychological burden.

This study is the first to assess the prevalence of psychological distress among pediatricians in Saudi Arabia, but as with any study, the limitations should be mentioned. They include the use of a self-reporting questionnaire and the lack of external validity due to limiting the assessment to only pediatricians in the western region of Saudi Arabia.

\section{Conclusions}

Pediatricians in Saudi Arabia are experiencing high levels of burnout, depression, anxiety and stress, which is accentuated among female, junior and young pediatricians. This distress is suggested to lead to negative effects on the quality of care provided to patients. We urge hospitals to take this seriously and begin designing psychological programs and support to help improve the psychological well-being of Saudi pediatricians. It is also crucial that pediatricians consider the significance of such problem affecting their health, and potentially their patients, in the long term of their career and make some efforts to manage such distress or refer to more professional psychological services. 
Source of funding: This work was funded from the authors' own resources.

Conflicts of interest: The authors declare no conflicts of interest.

\section{References}

1. Kansoun Z, Boyer L, Hodgkinson M, et al. Burnout in French physicians: a systematic review and meta-analysis. J Affect Disord 2019; 246: 132-147, doi: 10.1016/j.jad.2018.12.056.

2. Mata DA, Ramos MA, Bansal N, et al. Prevalence of depression and depressive symptoms among resident physicians: a systematic review and meta-analysis. JAMA 2015; 314(22): 2373-2383, doi: 10.1001/jama.2015.15845.

3. Rotenstein LS, Torre M, Ramos MA, et al. Prevalence of burnout among physicians: a systematic review. JAMA 2018; 320(11): 1131-1150, doi: 10.1001/jama.2018.12777.

4. Tironi MOS, Barbosa GB, Rocha GS, et al. Systematic review on the prevalence of Burnout Syndrome in intensivist physicians. Int $J$ Health Educ 2018; 2(1): 104-113, doi: 10.17267/2594-7907ijhe.v2i1.1950.

5. Brazeau CM, Schroeder R, Rovi S, et al. Relationships between medical student burnout, empathy, and professionalism climate. Acad Med 2010; 85(10): S33-S36, doi: 10.1097/ACM.0b013e3181ed4c47.

6. Oliveira GS de, Chang R, Fitzgerald PC, et al. The prevalence of burnout and depression and their association with adherence to safety and practice standards: a survey of United States anesthesiology trainees. Anesth Analg 2013; 117(1): 182-193, doi: 10.1213/ ANE.0b013e3182917da9.

7. Dyrbye LN, West CP, Satele D, et al. Burnout among US medical students, residents, and early career physicians relative to the general US population. Acad Med 2014; 89(3): 443-451, doi: 10.1097/ACM.0000000000000134.

8. Kushnir T, Cohen AH. Job structure and burnout among primary care pediatricians. Work 2006; 27(1): 67-74.

9. Scheepers RA, Boerebach BC, Arah OA, et al. A systematic review of the impact of physicians' occupational well-being on the quality of patient care. Int J Behav Med 2015; 22(6): 683-698, doi: 10.1007/s12529-015-9473-3.

10. Shanafelt TD, Balch CM, Bechamps G, et al. Burnout and medical errors among American surgeons. Ann Surg 2010; 251(6): 995-1000, doi: 10.1097/SLA.0b013e3181bfdab3.

11. Waheed K, Liaqat N, Ejaz S, et al. Burnout among gynaecological residents in Lahore, Pakistan: a cross-sectional survey. J Pak Med Assoc 2017; 67(9): 1318-1322.

12. Weigl M, Schneider A, Hoffmann F, et al. Work stress, burnout, and perceived quality of care: a cross-sectional study among hospital pediatricians. Eur J Pediatr 2015; 174(9): 1237-1246, doi: 10.1007/s00431-015-2529-1.

13. Dewa CS, Jacobs $P$, Thanh NX, et al. An estimate of the cost of burnout on early retirement and reduction in clinical hours of practicing physicians in Canada. BMC Health Serv Res 2014; 14(1): 254, doi: 10.1186/1472-6963-14-254.

14. Steijn ME van, Scheepstra KWF, Yasar G,et al. Occupational well-being in pediatricians - a survey about work-related posttraumatic stress, depression, and anxiety. Eur J Pediatr 2019; 178(5): 681-693, doi: 10.1007/s00431-019-03334-7.

15. Bari A, Kamran R, Haroon F, et al. Burnout among pediatric residents and junior consultants working at a tertiary care hospital. Pak J Med Sci 2019; 35(1): 45-49, doi: 10.12669/pjms.35.1.43.

16. Kotb AA, Mohamed KAE, Kamel MH, et al. Comparison of burnout pattern between hospital physicians and family physicians working in Suez Canal University Hospitals. Pan Afr Med J 2014; 18: 164, doi: 10.11605/pamj.2014.18.164.3355.

17. Shanafelt TD, Boone S, Tan L, et al. Burnout and satisfaction with work-life balance among US physicians relative to the general US population. Arch Intern Med 2012; 172(18): 1377-1385, doi: 10.1001/archinternmed.2012.3199.

18. Fahrenkopf AM, Sectish TC, Barger LK, et al. Rates of medication errors among depressed and burnt out residents: prospective cohort study. BMJ 2008; 336(7642): 488-491, doi: 10.1136/bmj.39469.763218.BE.

19. Garcia TT, Garcia PCR, Molon ME, et al. Prevalence of burnout in pediatric intensivists: an observational comparison with general pediatricians. Pediatr Crit Care Med 2014; 15(8): e347-e353, doi: 10.1097/PCC.000000000000218.

20. Pantaleoni JL, Augustine EM, Sourkes BM, et al. Burnout in pediatric residents over a 2-year period: a longitudinal study. Acad Pediatr 2014; 14(2): 167-172, doi: 10.1016/j.acap.2013.12.001.

21. Shanafelt TD, Hasan O, Dyrbye LN, et al. Changes in burnout and satisfaction with work-life balance in physicians and the general US working population between 2011 and 2014. Mayo Clin Proc 2015; 90(12): 1600-1613, doi: 10.1016/j.mayocp.2015.08.023.

22. Shanafelt TD, West CP, Sinsky C, et al. Changes in burnout and satisfaction with work-life integration in physicians and the general US working population between 2011 and 2017. Mayo Clin Proc 2019; 94(9): 1681-1694, doi: 10.1016/j.mayocp.2018.10.023.

23. Starmer AJ, Frintner MP, Freed GL. Work-life balance, burnout, and satisfaction of early career pediatricians. Pediatrics 2015; 137(4): e20153183, doi: 10.1542/peds.2015-3183.

24. Tawfik DS, Phibbs CS, Sexton JB, et al. Factors associated with provider burnout in the NICU. Pediatrics 2017; 139(5): e20164134, doi: 10.1542/peds.2016-4134.

25. Maslach C, Jackson SE. The measurement of experienced burnout. J Organ Behav 1981; 2(2): 99-113.

26. Branco RG, Garcia TT, Molon ME, et al. 1138 Burnout syndrome among pediatricians: a case control study comparing pediatric intensivists and general pediatricians. Pediatr Res 2010; 68(1): 564.

27. Aboalshamat $\mathrm{K}$, Alzahrani $\mathrm{M}$, Rabie $\mathrm{N}$, et al. The relationship between burnout and perfectionism in medical and dental students in Saudi Arabia. J Dent Specialities 2017; 5(2): 122-127.

28. Aboalshamat K, Hou XY, Strodl E. Psychological health of medical and dental students in Saudi Arabia: a longitudinal study. Public Health Research 2014; 4(5): 179-184, doi: 10.5923/j.phr.20140405.05.

29. Aboalshamat K, Hou XY, Strodl E. Psychological well-being status among medical and dental students in Makkah, Saudi Arabia: a crosssectional study. Med Teach 2015; 37(Suppl. 1): S75-S81.

30. Aboalshamat K, Jawhari A, Alotibi S, et al. Relationship of self-esteem with depression, anxiety, and stress among dental and medical students in Jeddah, Saudi Arabia. JIMD 2017; 4: 61-68, doi: 10.18320/JIMD/201704.0261.

31. Kristensen TS, Borritz M, Villadsen E, et al. The Copenhagen Burnout Inventory: a new tool for the assessment of burnout. Work Stress 2005; 19(3): 192-207, doi: 10.1080/02678370500297720.

32. Creedy DK, Sidebotham M, Gamble J, et al. Prevalence of burnout, depression, anxiety and stress in Australian midwives: a crosssectional survey. BMC Pregnancy Childbirth 2017; 17(1): 13, doi: 10.1186/s12884-016-1212-5.

33. Lovibond PF, Lovibond SH. The structure of negative emotional states: comparison of the Depression Anxiety Stress Scales (DASS) with the Beck Depression and Anxiety Inventories. Behav Res Ther 1995; 33(3): 335-343, doi: 10.1016/0005-7967(94)00075-u.

34. Henry JD, Crawford JR. The short-form version of the Depression Anxiety Stress Scales (DASS-21): construct validity and normative data in a large non-clinical sample. Br J Clin Psychol 2005; 44(2): 227-239, doi: 10.1348/014466505X29657.

35. Büssing A, Perrar KM. Measurement of burnout: the German version of the Maslach Burnout Inventory (MBI-D). Diagnostica 1992; 38(4): 328-353. 
36. Feeks C, Chao J, Sinert R. Prevalence and risk factors for burnout in pediatric emergency medicine fellows. Pediatr Emerg Care 2020, doi: 10.1097/PEC.0000000000002093.

37. Maslach C, Jackson SE, Leiter MP, et al. Maslach burnout inventory (Vol. 21). Palo Alto (CA): Consulting Psychologists Press; 1986.

38. Maslach C, Schaufeli WB, Leiter MP. Job burnout. Annu Rev Psychol 2001; 52(1): 397-422, doi: 10.1146/annurev.psych.52.1.397.

39. Borritz M, Kristensen TS. Copenhagen burnout inventory. Copenhagen: National Institute of Occupational Health; 1999.

40. Zhou P, Yang XL, Wang XG, et al. A pneumonia outbreak associated with a new coronavirus of probable bat origin. Nature 2020; 579(7798): 270-273, doi: 10.1038/s41586-020-2012-7.

41. Dai Y, Hu G, Xiong H, et al. Psychological impact of the coronavirus disease 2019 (COVID-19) outbreak on healthcare workers in China. medRxiv 2020, doi: 10.1101/2020.03.03.20030874.

42. Kang L, Ma S, Chen M, et al. Impact on mental health and perceptions of psychological care among medical and nursing staff in Wuhan during the 2019 novel coronavirus disease outbreak: a cross-sectional study. Brain Behav Immun 2020, doi: 10.1016/j.bbi.2020.03.028.

43. Center C, Davis M, Detre T, et al. Confronting depression and suicide in physicians: a consensus statement. JAMA 2003; 289(23): 3161-3166, doi: 10.1001/jama.289.23.3161.

44. Schernhammer ES, Colditz GA. Suicide rates among physicians: a quantitative and gender assessment (meta-analysis). Am J Psychiatry 2004; 161(12): 2295-2302, doi: 10.1176/appi.ajp.161.12.2295.

45. Wada K, Yoshikawa T, Goto T, et al. Association of depression and suicidal ideation with unreasonable patient demands and complaints among Japanese physicians: a national cross-sectional survey. Int J Behav Med 2011; 18(4): 384-390, doi: 10.1007/s12529-010-9132-7.

46. Kvrgic S, Harhaji S, Jovanovic VM, et al. Gender differences in mental health among adult population in Vojvodina, Serbia. Iran J Public Health 2013; 42(8): 833-841.

47. Bourbonnais R, Brisson C, Vézina M. Long-term effects of an intervention on psychosocial work factors among healthcare professionals in a hospital setting. Occup Environ Med 2011; 68(7): 479-486, doi: 10.1136/oem.2010.055202.

48. Weigl $\mathrm{M}$, Hornung $\mathrm{S}$, Angerer $\mathrm{P}$, et al. The effects of improving hospital physicians working conditions on patient care: a prospective, controlled intervention study. BMC Health Serv Res 2013; 13(1): 401, doi: 10.1186/1472-6963-13-401.

49. Aboalshamat K, Hou XY, Strodl E. The impact of a self-development coaching programme on medical and dental students' psychological health and academic performance: a randomised controlled trial. BMC Med Educ 2015; 15(1): 134, doi: 10.1186/s12909-015-0412-4.

Tables: 5

Figures: 0

References: 49

Received: 27.12.2020

Reviewed: 17.01.2021

Accepted: 8.03 .2021

Address for correspondence:

Rana Mohammed Rahimaldeen, MD

Batterjee Medical College

Jeddah

Saudi Arabia

Tel.: +96 6553373778

E-mail: ranarahimaldeen@gmail.com 